\title{
Phenotypic and Genotypic Analyses of Drought Tolerance in Korean and Tunisian Wheat Cultivars
}

\author{
Sang Heon Kim ${ }^{1}$, Dae Yeon $\mathrm{Kim}^{2}$, Inés Yacoubi ${ }^{3}$, Yong Weon Seo ${ }^{1,2 *}$ \\ ${ }^{1}$ Department of Biosystems and Biotechnology, Korea University, Seoul 136-713, Korea \\ ${ }^{2}$ Division of Biotechnology, Korea University, Seoul 136-713, Korea \\ ${ }^{3}$ Centre of Biotechnology of Sfax, B.P K.3038 Sfax, Tunisia
}

\begin{abstract}
Common wheat (Triticum aestivum L.) and durum wheat (T. turgidum L. subsp. Durum) are major staple food crops in the world. However, their production are limited by environmental stress such as drought. In order to evaluate wheat's response to drought, a total of 77 common wheat and durum wheat consisted of 19 Korean common wheat, 30 Tunisian common wheat and 28 Tunisian durum wheat were used in this study. Drought stress was applied for 21 days by suspending water application starting at the third leaf-expansion stage, followed by watering for the recovery of wheat until harvesting. Phenotypic parameters such as plant height, leaf length, tiller number, chlorophyll content, days to flowering and dry weight were scored during and after the treatment. Drought tolerance trait index (DTTI) and drought tolerance index (DTI) were calculated and used as criteria for selection of drought tolerance. At the end of treatment, most of the parameters except tiller numbers significantly decreased. Even after re-watering, plant height, leaf length, and dry weight continuously decreased. However, leaf chlorophyll content, and days to flowering of both stressed and non-stressed plants showed no significant differences. A total of 17 drought tolerance related simple sequence repeats (SSR) markers were used to identify genetic distance between Korean and Tunisian cultivars and elucidate possible use of marker systems for drought resistance. The common wheat and durum wheat cultivars formed different clusters for drought tolerance (resistance, moderate resistance, susceptible) using the SSR data. The results obtained in this study could help to increase genetic resources and breeding program for drought tolerance.
\end{abstract}

Keywords Common wheat, Drought tolerance, Durum wheat, SSR marker

\section{INTRODUCTION}

There is a current concern for future global food production using crops amidst an increasing world population (Brown \& Funk 2008). Environmental problems such as drought, floods, and salinity have been reported to be more severe in some areas. In semi-arid areas, it is predicted that the grain yield of main cereal crops such as wheat and rice would decrease in the following 20 years (Lobell et al. 2008). To overcome these problems, crop improvements not only to increase yield but also to enhance tolerance to environmental stress are needed to improve global food security (Takeda \& Matsuoka 2008).

Wheat (Triticum spp.) is a major staple food crop around the world (Munns et al. 2006). Common wheat (T. aestivum
L.) and durum wheat (T. turgidum L. subsp. Durum) are major species of cultivated wheat. Drought stress is one of the global problems that limit crop production (Pan et al. 2002). About $32 \%$ of the wheat cultivating regions in developing countries experience drought stress during the growing season (Rajaram 2001).

Microsatellites or simple sequence repeats (SSR) have been widely utilized in plants as molecular markers for specific phenotypic traits (Gupta \& Varshney 2000). Marker-assisted selection is useful for improving drought tolerance in wheat (Quarrie et al. 2003). SSR markers can show the genetic diversity for drought stress in wheat (El Siddig et al. 2013).

Recent studies involving in vitro selection using polyethylene glycol (PEG) or mannitol applied to generate

Received April 27, 2014; Revised May 10, 2014; Accepted May 27, 2014; Published June 30, 2014

*Corresponding author Yong Weon Seo, seoag@korea.ac.kr, Tel: +82-2-3290-3005, Fax: +82-2-3290-3501 
water stress in plants were performed to develop droughttolerant plants (Rai et al. 2011). However, some results of in vivo and in vitro studies are not necessarily associated and had to be considered individually (Farshadfar et al. 2012). Further, plant responses to PEG treatment could not indicate the drought tolerance for the entire plant growth period. Drought stress is a limiting factor to plant growth and dry matter (Jaleel et al. 2009); therefore, morphological traits can be used as a criteria for drought tolerance.

Korea is located in East Asia. The winter climate is cold and dry, whereas it is hot and humid during summer. In Korea, wheat is cultivated as a winter crop. Accordingly, wheat is subjected to drought stress during its early stages of growth in Korea.

Tunisia is located in North Africa; it is bordered by the Mediterranean Sea on the north and east, whereas the Sahara desert is positioned to its south. The climate in the north is warm with dry summer climate (Mediterranean climate), whereas the climate in the mid-south is semi-arid, where soil moisture barely meets wheat seedling growth and rainfall is low. Thus, in Tunisia, wheat experiences drought stress during its entire growing period.

The main objective of this study was to screen Korean common wheat, Tunisian common wheat, and Tunisian durum wheat cultivars for drought tolerance by using morphological traits and SSR markers to utilize them for future breeding programs.

\section{MATERIALS AND METHODS}

\section{Plant materials and experimental conditions}

A total of 77 cultivars ( 49 common wheat lines and 28 durum wheat lines) were used in this study. Of these, 19 lines were Korean common wheat, and 58 lines were Tunisian wheat. Seeds of Korean wheat cultivars were provided by the National Institute of Crop Science (NICS), Rural Development Administration (RDA) of Korea. The Tunisian seeds were obtained from the National Agrobiodiversity Center (NAC), RDA and the National Plant Germplasm

Table 1. The list of wheat cultivars used in this study.

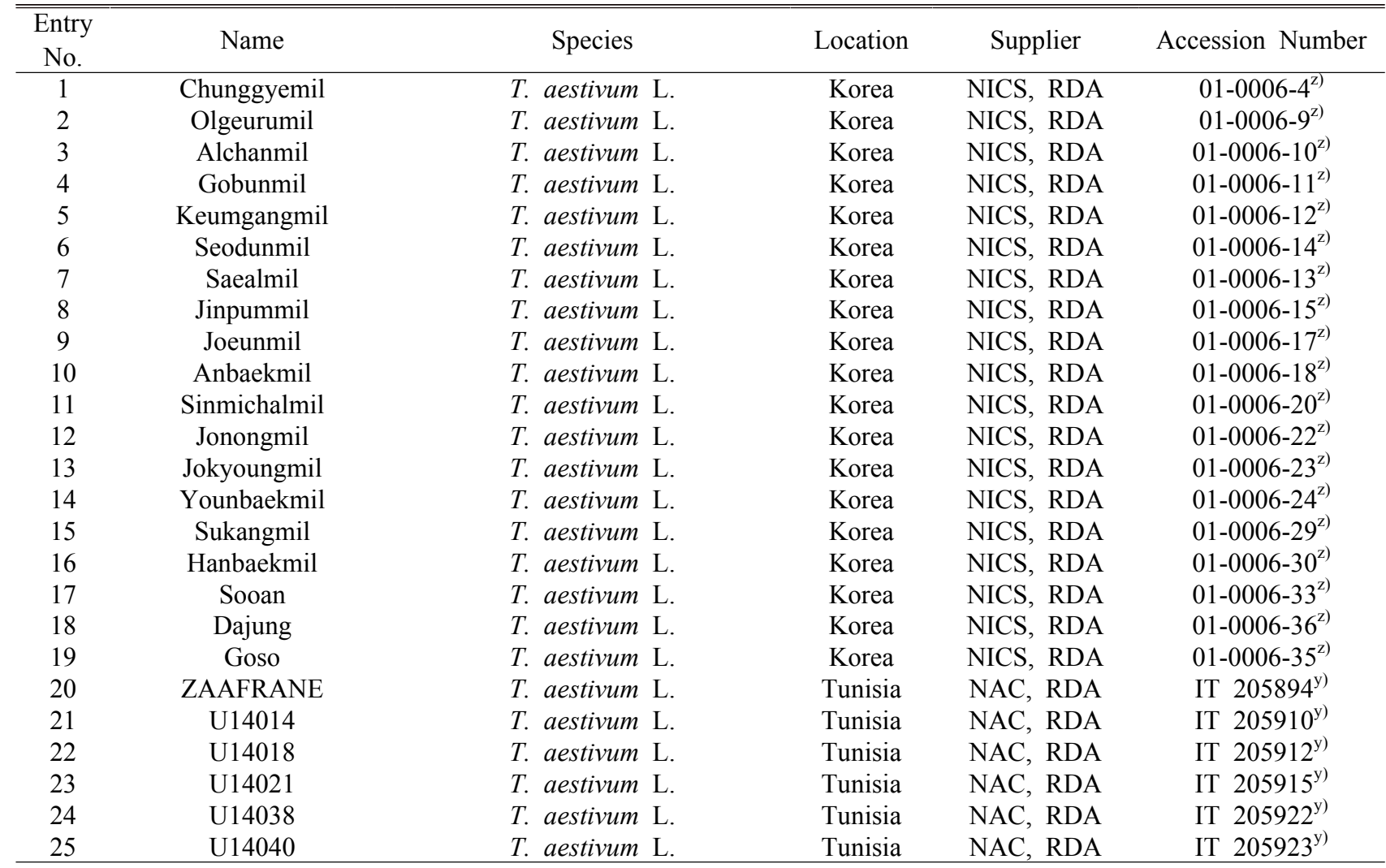


Table 1. Continued.

\begin{tabular}{|c|c|c|c|c|c|}
\hline $\begin{array}{c}\text { Entry } \\
\text { No. }\end{array}$ & Name & Species & Location & Supplier & Accession Number \\
\hline 26 & U14045 & T. aestivum L. & Tunisia & NAC, RDA & IT $205926^{\mathrm{y})}$ \\
\hline 27 & U14046 & T. aestivum $\mathrm{L}$. & Tunisia & NAC, RDA & IT $205927^{\text {y) }}$ \\
\hline 28 & U14054 & T. aestivum $\mathrm{L}$. & Tunisia & NAC, RDA & IT $205933^{\mathrm{y})}$ \\
\hline 29 & U14057 & T. aestivum $\mathrm{L}$. & Tunisia & NAC, RDA & IT $205935^{\mathrm{y})}$ \\
\hline 30 & U14076 & T. aestivum L. & Tunisia & NAC, RDA & IT $205938^{\mathrm{y})}$ \\
\hline 31 & FRIGUI 2 & T. aestivum L. & Tunisia & NAC, RDA & IT $229475^{\mathrm{y})}$ \\
\hline 32 & U14010 & T. turgidum L. subsp. Durum & Tunisia & NAC, RDA & IT $205908^{\mathrm{y})}$ \\
\hline 33 & U14031 & T. turgidum L. subsp. Durum & Tunisia & NAC, RDA & IT $205917^{\mathrm{y})}$ \\
\hline 34 & U14050 & T. turgidum L. subsp. Durum & Tunisia & NAC, RDA & IT $205929^{\mathrm{y})}$ \\
\hline 35 & U14053 & T. turgidum L. subsp. Durum & Tunisia & NAC, RDA & IT $205932^{\mathrm{y})}$ \\
\hline 36 & U14055 & T. turgidum L. subsp. Durum & Tunisia & NAC, RDA & IT $205934^{\mathrm{y})}$ \\
\hline 37 & U14078 & T. turgidum L. subsp. Durum & Tunisia & NAC, RDA & IT $205940^{\mathrm{y})}$ \\
\hline 38 & SINLIKAT & T. turgidum L. subsp. Durum & Tunisia & NAC, RDA & IT $205941^{\mathrm{y})}$ \\
\hline 39 & AGIM SINLIKA & T. turgidum L. subsp. Durum & Tunisia & $\mathrm{NAC}, \mathrm{RDA}$ & IT $205943^{\mathrm{y})}$ \\
\hline 40 & MELANGE & T. turgidum L. subsp. Durum & Tunisia & NAC, RDA & IT $205944^{\mathrm{y})}$ \\
\hline 41 & BEDI & T. turgidum L. subsp. Durum & Tunisia & NAC, RDA & IT $205947^{\mathrm{y})}$ \\
\hline 42 & Allorca & T. aestivum L. & Tunisia & NPGS, USDA & PI $41032^{\mathrm{x})}$ \\
\hline 43 & Florence Aurore & T. aestivum $\mathrm{L}$. & Tunisia & NPGS, USDA & PI $150608^{x)}$ \\
\hline 44 & Florence Aurore & T. aestivum $\mathrm{L}$. & Tunisia & NPGS, USDA & PI $\left.150609^{x}\right)$ \\
\hline 45 & Koudiat A2 & T. aestivum $\mathrm{L}$. & Tunisia & NPGS, USDA & PI $174665^{\mathrm{x})}$ \\
\hline 46 & Florence 135 & T. aestivum L. & Tunisia & NPGS, USDA & PI $185357^{\mathrm{x})}$ \\
\hline 47 & Mahon 73 & T. aestivum L. & Tunisia & NPGS, USDA & PI $185372^{\mathrm{x})}$ \\
\hline 48 & Mahon 124 & T. aestivum L. & Tunisia & NPGS, USDA & PI $185373^{\mathrm{x})}$ \\
\hline 49 & Roussla & T. aestivum L. & Tunisia & NPGS, USDA & PI $189775^{\mathrm{x})}$ \\
\hline 50 & Cailloux & T. aestivum L. & Tunisia & NPGS, USDA & PI $191446^{\mathrm{x})}$ \\
\hline 51 & Mahon 73 & T. aestivum L. & Tunisia & NPGS, USDA & PI $191734^{\mathrm{x})}$ \\
\hline 52 & Irakie 231 & T. aestivum L. & Tunisia & NPGS, USDA & PI $191738^{x)}$ \\
\hline 53 & Mahon 124 & T. aestivum $\mathrm{L}$. & Tunisia & NPGS, USDA & PI $191929^{x)}$ \\
\hline 54 & Mahon 73 & T. aestivum L. & Tunisia & NPGS, USDA & PI $192024^{\mathrm{x})}$ \\
\hline 55 & Cailloux & T. aestivum $\mathrm{L}$. & Tunisia & NPGS, USDA & PI $304915^{\mathrm{x}}$ \\
\hline 56 & Baroota 52 & T. aestivum L. & Tunisia & NPGS, USDA & PI $410889^{\mathrm{x})}$ \\
\hline 57 & Soltane & T. aestivum $\mathrm{L}$. & Tunisia & NPGS, USDA & PI $428416^{\mathrm{x})}$ \\
\hline 58 & Ariana 66 & T. aestivum L. & Tunisia & NPGS, USDA & PI $519955^{\mathrm{x})}$ \\
\hline 59 & BT 2288 & T. aestivum L. & Tunisia & NPGS, USDA & PI $559656^{\mathrm{x})}$ \\
\hline 60 & Huguenot Bariole 360 & T. turgidum L. subsp. Durum & Tunisia & NPGS, USDA & PI $174646^{\mathrm{x})}$ \\
\hline 61 & Jenah Retifah 24 & T. turgidum L. subsp. Durum & Tunisia & NPGS, USDA & PI $184537^{\mathrm{x})}$ \\
\hline 62 & Mekki 13 & T. turgidum L. subsp. Durum & Tunisia & NPGS, USDA & PI $185194^{\mathrm{x})}$ \\
\hline 63 & Sbei 7 & T. turgidum L. subsp. Durum & Tunisia & NPGS, USDA & PI $185195^{\mathrm{x})}$ \\
\hline 64 & Ble Dur 116 & T. turgidum L. subsp. Durum & Tunisia & NPGS, USDA & PI $189772^{\mathrm{x})}$ \\
\hline 65 & Ble Dur 870 & T. turgidum L. subsp. Durum & Tunisia & NPGS, USDA & PI $189773^{\mathrm{x})}$ \\
\hline 66 & Jenah Retifah 1 & T. turgidum L. subsp. Durum & Tunisia & NPGS, USDA & PI $192516^{\mathrm{x})}$ \\
\hline 67 & Jenah Retifah 24 & T. turgidum L. subsp. Durum & Tunisia & NPGS, USDA & PI $192517^{\mathrm{x})}$ \\
\hline 68 & Sbei 272 & T. turgidum L. subsp. Durum & Tunisia & NPGS, USDA & PI $278383^{\mathrm{x})}$ \\
\hline 69 & Mahmoudi & T. turgidum L. subsp. Durum & Tunisia & NPGS, USDA & PI $306573^{x)}$ \\
\hline 70 & Inrat 69 & T. turgidum L. subsp. Durum & Tunisia & NPGS, USDA & PI $324939^{x}$ \\
\hline 71 & Maghrebi & T. turgidum L. subsp. Durum & Tunisia & NPGS, USDA & PI $422313^{\mathrm{x})}$ \\
\hline 72 & Roussia & T. turgidum L. subsp. Durum & Tunisia & NPGS, USDA & PI $428434^{\mathrm{x})}$ \\
\hline 73 & Maghrebi 72 & T. turgidum L. subsp. Durum & Tunisia & NPGS, USDA & PI $428462^{x)}$ \\
\hline 74 & Amal 72 & T. turgidum L. subsp. Durum & Tunisia & NPGS, USDA & PI $433749^{\mathrm{x})}$ \\
\hline 75 & Badri & T. turgidum L. subsp. Durum & Tunisia & NPGS, USDA & PI $433751^{\mathrm{x})}$ \\
\hline 76 & Maghrebi 72 & T. turgidum L. subsp. Durum & Tunisia & NPGS, USDA & PI $433758^{\mathrm{x})}$ \\
\hline 77 & Maghrebi 72 & T. turgidum L. subsp. Durum & Tunisia & NPGS, USDA & PI $520062^{x)}$ \\
\hline
\end{tabular}

${ }^{\text {z) }}$ The registration number of cultivar in Korea Seed \& Variety Service (KSVS) (http://www.seed.go.kr).

${ }^{\text {y) }}$ The IT accession number in the RDA-Genebank Information Center (http://www.genebank.go.kr/)

${ }^{\mathrm{x})}$ The PI accession number in the ARS-GRIN (http://www.ars-grin.gov/). 
System (NPGS), United States Department of Agriculture (USDA). Information about the Tunisian common wheat and durum wheat accessions was obtained from the RDA-Genebank Information Center (http://www.genebank. go.kr/) and the Agricultural Research Service-Germplasm Resources Information Network (ARS-GRIN) (http://www. ars-grin.gov/).

The experiment was conducted during the 2013 growing season at the greenhouse of the Research Farm of Korea University (Namyangju-si, Gyeonggi-do, Korea). Two seeds were planted per pot $(5,5,16 \mathrm{~cm}$ ) filled with soil (Sunshine mix \#1). Immediately after emergence, seedlings were thinned out to let each plant grow in each pot. Five plants per line from each control and treatment groups were subjected to the test.

All plants were grown with sufficient watering until the drought treatment was initiated. Drought stress was imposed at the fully expanded third leaf stage by suspending water application, whereas plants in the non-stressed condition received sufficient water every two days. The treatment was applied for three weeks. After the treatment, all plants were provided with sufficient water and grown until spike harvest.

\section{Morphological traits measurement}

Phenotypic parameters such as plant height, average leaf length, number of tillers per plant, and leaf chlorophyll content were measured at three time points (the initiation of treatment, the end of treatment, and 28 days after the end of treatment). The first measurement was used for normalization, and the others were used in calculating the degree of recovery after drought stress. Days to flowering and shoot dry weight were also scored.

Leaf chlorophyll content was recorded by using a portable chlorophyll meter (SPAD-502, Minolta, Japan). SPAD-502 can measure leaf chlorophyll content in a fast and nondestructive way (Yıldırım et al. 2001). Drought tolerance trait index (DTTI) and drought tolerance index (DTI) were calculated using the formula of Shahzad et al. (2012) and Ali et al. (2007). If the mean DTTI for a trait was $>100$, it indicates that the trait would increase during drought stress. Thus, the reciprocal of DTTI was used to calculate DTI.

$$
\text { DTTI }=\frac{\text { Value of trait under stress condition }}{\text { Value of trait under non }- \text { stress condition }} \times 100
$$

DTI $=$ The average of DTTIs

Table 2. The list of SSR markers used in this study.

\begin{tabular}{|c|c|c|c|}
\hline Name & F Primer & R Primer & $\begin{array}{c}\text { Annealing } \\
\text { Temperature }\left({ }^{\circ} \mathrm{C}\right)\end{array}$ \\
\hline Xbarc108 & GCGGGTCGTTTCCTGGAAATTCATCTAA & GCGAAATGATTGGCGTTACACCTGTTG & 50 \\
\hline Xbarc121 & ACTGATCAGCAATGTCAACTGAA & CCGGTGTCTTTCCTAACGCTATG & 50 \\
\hline Xgwm573 & AAGAGATAACATGCAAGAAA & TTCAAATATGTGGGAACTAC & 50 \\
\hline Xgwm130 & AGCTCTGCTTCACGAGGAAG & СТCCTCTTTATATCGCGTCCC & 60 \\
\hline Xgwm332 & AGCCAGCAAGTCACCAAAAC & AGTGCTGGAAAGAGTAGTGAAGC & 60 \\
\hline Xgwm635 & TTCCTCACTGTAAGGGCGTT & CAGCCTTAGCCTTGGCG & 60 \\
\hline$X w m c 233$ & GACGTCAAGAATCTTCGTCGGA & ATCTGCTGAGCAGATCGTGGTT & 61 \\
\hline Xwmc 9 & AACTAGTCAAATAGTCGTGTCCG & GTCAAGTCATCTGACTTAACCCG & 61 \\
\hline Xwmc596 & TCAGCAACAAACATGCTCGG & CCCGTGTAGGCGGTAGCTCTT & 61 \\
\hline Xwmc603 & ACAAACGGTGACAATGCAAGGA & CGCCTCTCTCGTAAGCCTCAAC & 61 \\
\hline Xwmc695 & GAGGGCACCTCGTAAGTTGG & GGCAGGAGCCCCTACAAGAT & 61 \\
\hline Xwmc65 & TGGATGGGAAGGAGAATAAGTG & ATCCAACCGGAACTACCGTCAG & 61 \\
\hline$X g w m 260$ & GCCCCCTTGCACAAATC & CGCAGCTACAGGAGGCC & 55 \\
\hline Xgwm350 & ACCTCATCCACATGTTCTACG & GCATGGATAGGACGCCC & 55 \\
\hline Xgwm276 & ATTTGCCTGAAGAAAATATT & AATTTCACTGCATACACAAG & 55 \\
\hline Xwmc17 & ACCTGCAAGAAATTAGGAACTC & CTAGTGTTTCAAATATGTCGGA & 51 \\
\hline$X w m c 182$ & GTATCTCACGAGCATAACACAA & GAAAGTGTATGGATCATTAGGC & 51 \\
\hline
\end{tabular}


DTI was calculated as the mean of DTTIs for morphological traits showing the tendency to drought stress and recovery. Based on DTI, drought tolerance of 77 common wheat and durum wheat cultivars was determined as resistant lines, moderate lines, and susceptible lines.

\section{SSR marker analysis}

A total of 17 SSR primers were used in the analysis (Table 2). Information on the markers was obtained from the Agricultural Research Service-GrainGenes 2.0 (http:// wheat.pw.usda.gov). Polymerase chain reactions (PCRs)

A

(a)

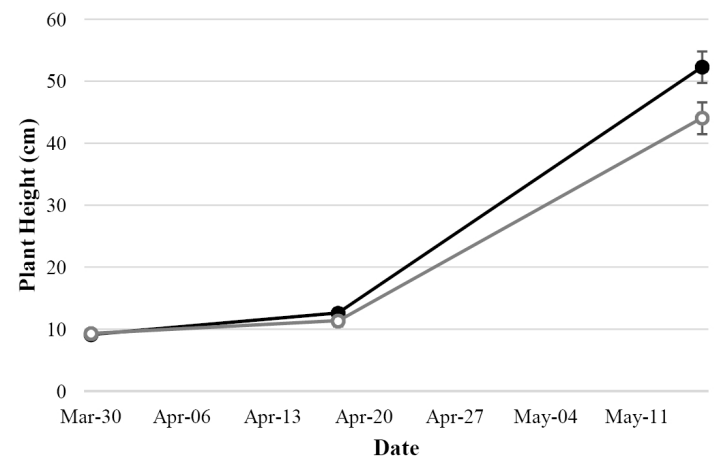

(b)

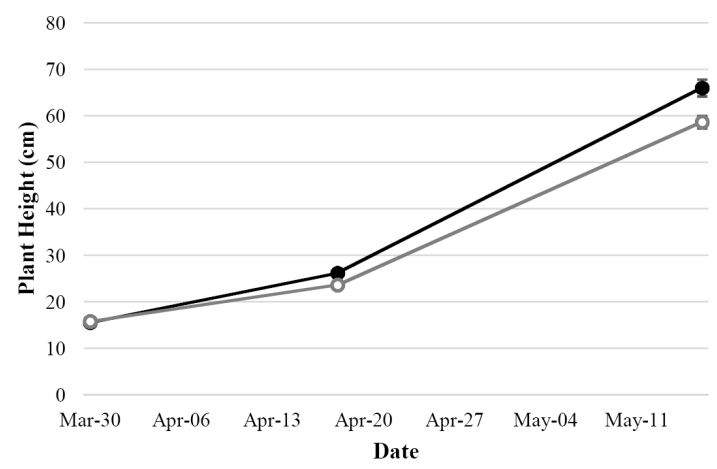

(c)

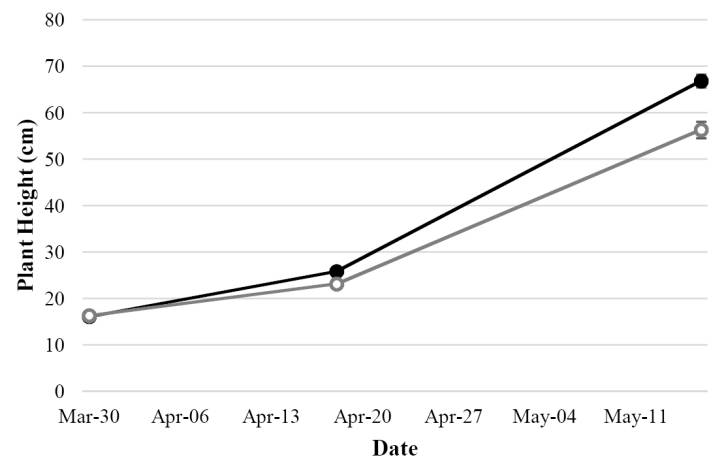

were performed as described by Ciucă \& Petcu (2009), with minor modification. PCR products were separated on agarose gel, and visualized and recorded using a gel documentation system.

The analysis was performed using the NTSYS-pc version 2.1 software using qualitative data for the similarity analysis, Sequential Agglomerative Hierarchical Nesting (SAHN) based on Unweighted Pair-Group Method with Arithmetic average (UPGMA) for the cluster analysis, and tree plot for the graphic visualization of dendrograms.
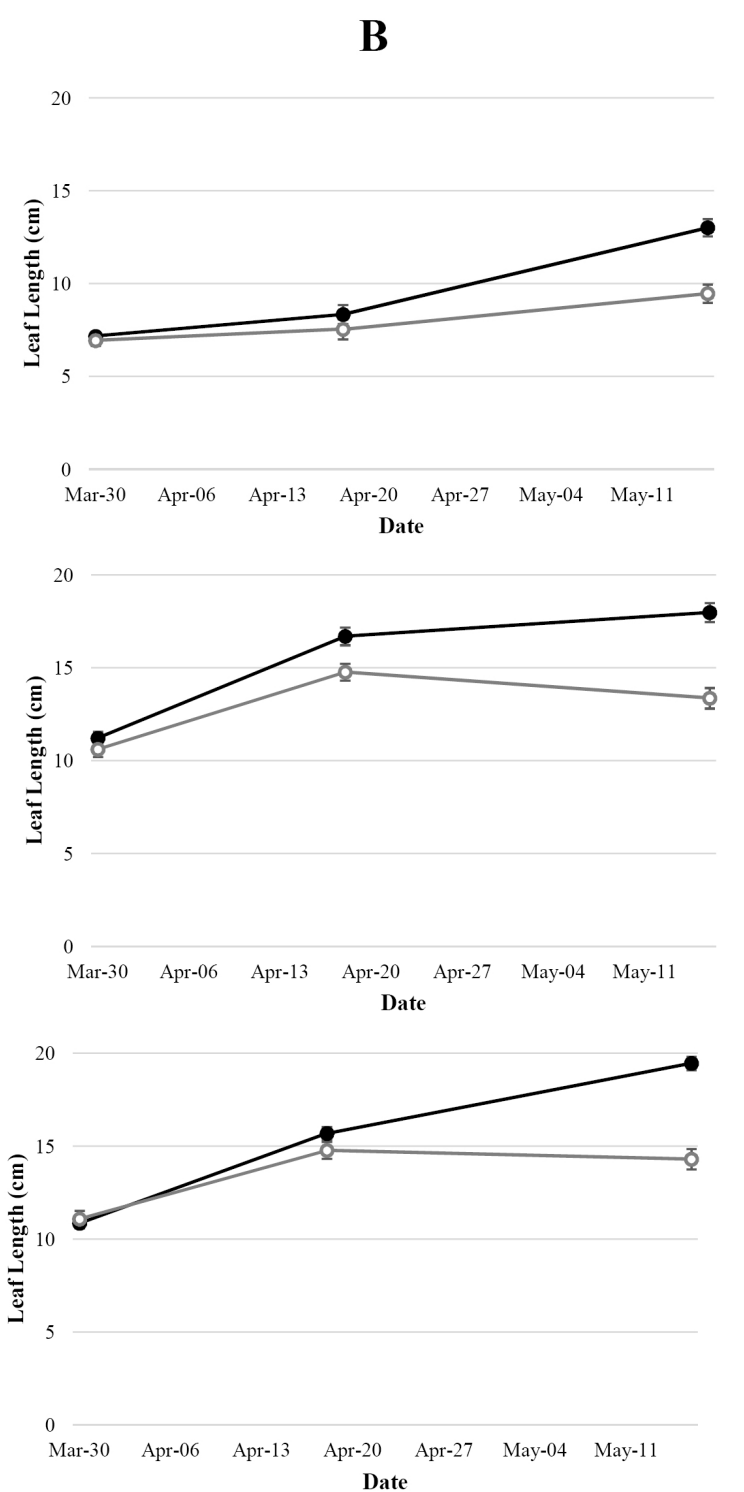

Fig. 1. Average plant height (A) and average leaf length (B) of Korean common wheat cultivars (a), Tunisian common wheat cultivars (b), and Tunisian durum wheat cultivars (c). Control (closed symbols) and treatment (open symbols). 


\section{RESULTS}

\section{Morphological traits measurement}

Agronomic traits of both control (non-stressed) and stressed plants were measured at three time points: at the initiation of the treatment, end of treatment (21 days without watering), and 28 days after the end of treatment. Compared to the non-stressed plant, plant height, leaf length, leaf chlorophyll content, and shoot dry weight of the treated plants decreased (Fig. 1A, B, and 2). Despite re-watering, the gap of those parameters between control and treatment increased.

(a)

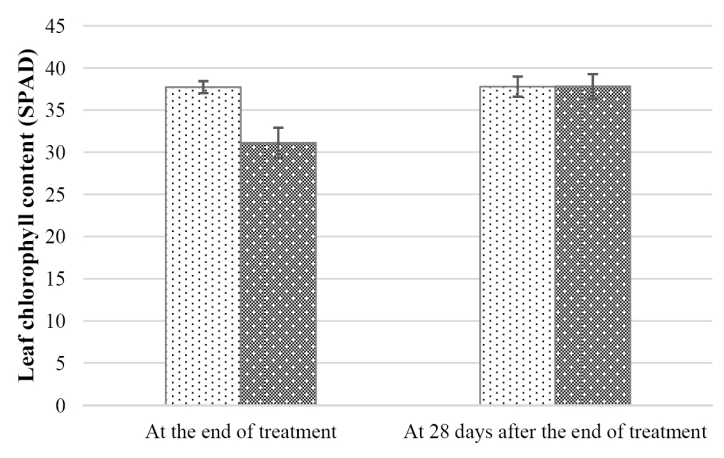

$\square$ Control $\mathbf{x}$ Treatment

(c)

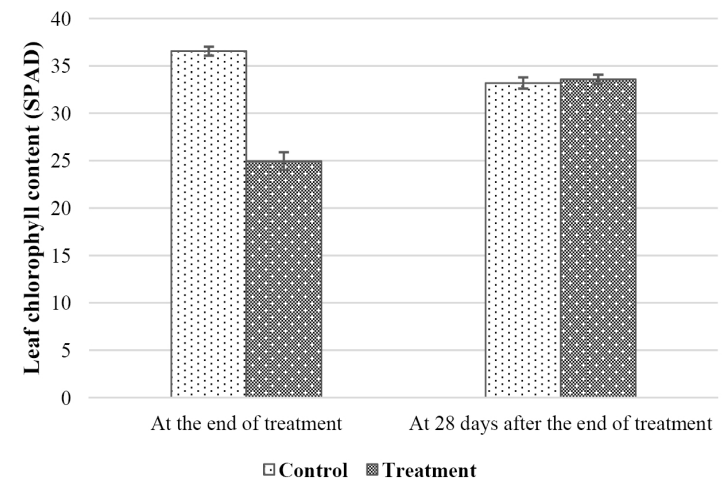

\section{DTTI analysis}

The magnitude of DTTI at the end of the treatment indicates the response of the plants to drought stress. At the end of the treatment, the mean DTTI for plant height was $88.3 \pm 1.57$. Tunisian durum wheat cultivars showed the highest plant height $(88.7 \pm 2.18 \%)$, followed by the Korean common wheat cultivars and Tunisian common wheat cultivars (Table 3 ). The mean DTTI for average leaf length was $93.2 \pm 1.88 \%$. Korean common wheat cultivars showed the highest leaf length $(94.7 \pm 5.49 \%)$ followed by the Tunisian common wheat cultivars and Tunisian durum wheat cultivars (Table 3 ). The mean DTTI for the number

(b)

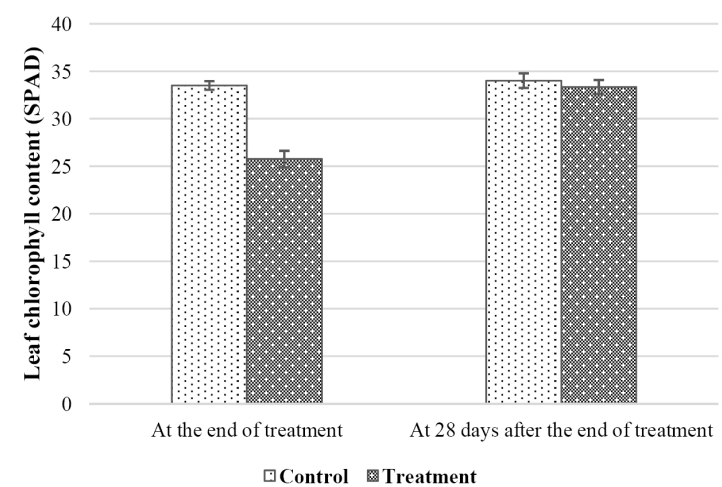

(d)

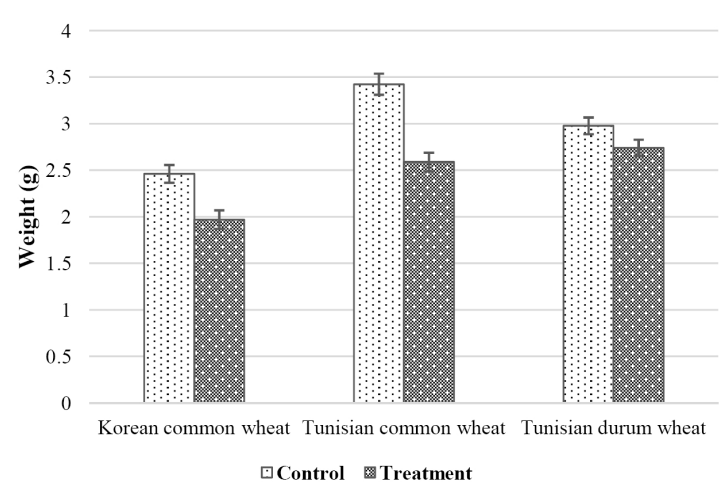

Fig. 2. Average leaf chlorophyll content of Korean common wheat cultivars (a), Tunisian common wheat cultivars (b), and Tunisian durum wheat cultivars (c), and shoot dry weight of each cultivar (d).

Table 3. Drought tolerance trait indices (DTTIs) at 21 days after drought treatment.

\begin{tabular}{ccccc}
\hline \hline Group & $\begin{array}{c}\text { Plant Height } \\
(\%)\end{array}$ & $\begin{array}{c}\text { Average Leaf Length } \\
(\%)\end{array}$ & $\begin{array}{c}\text { No. of Tillers } \\
(\%)\end{array}$ & $\begin{array}{c}\text { Leaf Chlorophyll Content } \\
(\%)\end{array}$ \\
\hline Korean common wheat & $88.5 \pm 3.70$ & $94.7 \pm 5.49$ & $109.1 \pm 4.33$ & $82.7 \pm 4.57$ \\
Tunisian common wheat & $87.9 \pm 2.67$ & $93.6 \pm 2.50$ & $98.3 \pm 6.63$ & $76.8 \pm 2.17$ \\
Tunisian durum wheat & $88.7 \pm 2.18$ & $91.9 \pm 2.56$ & $91.6 \pm 4.39$ & $68.6 \pm 2.74$ \\
\hline Total & $88.3 \pm 1.57$ & $93.2 \pm 1.88$ & $98.5 \pm 3.27$ & $75.3 \pm 1.82$ \\
\hline
\end{tabular}


of tillers was $98.5 \pm 3.27 \%$. Korean common wheat cultivars showed the highest number of tillers $(109.1 \pm 4.33 \%)$ followed by the Tunisian common wheat cultivars and Tunisian durum wheat cultivars (Table 3 ). The mean DTTI for leaf chlorophyll content was $75.3 \pm 1.82 \%$. Korean common wheat cultivars showed the highest leaf chlorophyll content $(82.7 \pm 4.57 \%)$, followed by the Tunisian common wheat cultivars and the Tunisian durum wheat cultivars (Table 3). Overall, DTTIs in most genotypes were $<100 \%$, except for the number of tillers in Korean common wheat cultivars.

The magnitude of DTTI at 30 days after the end of the treatment indicates the ability of plants to recover from the drought stress. At 28 days after the end of the treatment, the mean DTTI for plant height was $84.3 \pm 2.04 \%$. Tunisian common wheat cultivars showed the greatest plant height $(86.9 \pm 3.59 \%)$, followed by the Tunisian durum wheat cultivars and the Korean common wheat cultivars (Table 4). The mean DTTI for average leaf length was 75.5.2 \pm $2.60 \%$. Tunisian common wheat cultivars showed the highest leaf length $(79.3 \pm 4.03 \%)$, followed by the Korean common wheat and the Tunisian durum wheat cultivars (Table 4). The mean DTTI for the number of tillers was $132.5 \pm 6.72 \%$. Korean common wheat cultivars showed the highest number of tillers (154 $\pm 15.02 \%)$, followed by the Tunisian common wheat and the Tunisian durum wheat cultivars (Table 4). The mean DTTI for leaf chlorophyll content was $100.2 \pm 1.24 \%$. Tunisian durum wheat cultivars showed the highest leaf chlorophyll content $(101.9 \pm 2.14)$, followed by the Korean common wheat and Tunisian common wheat cultivars (Table 4). Compared to measurement at the end of the treatment, the mean DTTIs for plant height and average leaf length decreased, whereas those of the number of tillers per plant and leaf chlorophyll content increased.

For shoot dry weight, the mean DTTI was $84.2 \pm 2.22 \%$; the Tunisian durum wheat cultivars showed the highest shoot dry weights, followed by the Korean common wheat cultivars and Tunisian common wheat cultivars (Table 5). For days to flowering, the mean DTTI was $101.0 \pm 0.35 \%$ and the Tunisian durum wheat cultivars showed the highest values, followed by the Tunisian common wheat cultivars and Korean common wheat cultivars (Table 5). Most of the shoot dry weight in the treatment was lower than in the control, whereas the days to flowering in both the treatment and the control were almost same.

\section{Calculation of DTI and determination of drought tolerance}

The magnitude of DTI indicates a combined plant response using four parameters (plant height, average leaf length, leaf chlorophyll content, and dry shoot weight) and two stages (21 days after treatment and 28 days after the end of the treatment). The average DTI of 77 wheat cultivars

Table 4. Drought tolerance trait indices (DTTIs) at 28 days after re-watering.

\begin{tabular}{ccccc}
\hline \hline Group & $\begin{array}{c}\text { Plant Height } \\
(\%)\end{array}$ & $\begin{array}{c}\text { Average Leaf Length } \\
(\%)\end{array}$ & $\begin{array}{c}\text { No. of Tillers } \\
(\%)\end{array}$ & $\begin{array}{c}\text { Leaf Chlorophyll } \\
\text { Content }(\%)\end{array}$ \\
\hline Korean common wheat & $82.1 \pm 4.21$ & $76.1 \pm 5.8$ & $154 \pm 15.02$ & $100.3 \pm 2.83$ \\
Tunisian common wheat & $86.9 \pm 3.59$ & $79.3 \pm 4.03$ & $105.6 \pm 8.24$ & $98.5 \pm 1.74$ \\
Tunisian durum wheat & $83.1 \pm 2.99$ & $70.9 \pm 4.11$ & $146.8 \pm 11.03$ & $101.9 \pm 2.14$ \\
\hline Total & $84.3 \pm 2.04$ & $75.5 \pm 2.6$ & $132.5 \pm 6.72$ & $100.2 \pm 1.24$ \\
\hline
\end{tabular}

Table 5. Drought tolerance trait indices (DTTIs) for shoot dry weight and days to flowering.

\begin{tabular}{ccc}
\hline \hline Group & Shoot Dry Weight (\%) & Days to Flowering (\%) \\
\hline Korean common wheat & $83.2 \pm 6.09$ & $100.5 \pm 1.00$ \\
Tunisian common wheat & $76.8 \pm 3.04$ & $100.9 \pm 0.41$ \\
Tunisian durum wheat & $92.7 \pm 2.39$ & $101.5 \pm 0.51$ \\
\hline Total & $84.2 \pm 2.22$ & $101.0 \pm 0.35$ \\
\hline
\end{tabular}


was $85.5 \%$. Based on the magnitude of DTI, drought tolerance of the 77 wheat cultivars was determined as resistant lines (above 90\%), moderate lines (81-90\%), and susceptible lines (below 80\%). From the 77 cultivars, 23 lines were resistant, 33 lines were moderate, and 21 lines were susceptible (Table 6). Four cultivars that showed $>100 \%$ DTI were selected as the most resistant lines (Table 7).

\section{SSR analysis}

SSR analysis was performed to identify markers for drought tolerance. A dendrogram was constructed from the cluster analysis of similarity coefficients of SSR markers (Fig. 3). A total of 77 cultivars were classified into two groups: group A (comprised of Korean cultivars) and group
B (composed of Tunisian cultivars). Groups A and B were further categorized into three clusters each. Cluster A-1 is comprised of moderate resistant and resistant lines and had average DTI of $90.9 \pm 4.45 \%$. The average DTI of cluster A-2 was $72.4 \pm 5.52 \%$, which is comprised of mostly susceptible lines and a few moderate lines. The average DTI of cluster A-3 was $92.5 \pm 2.88 \%$, which is comprised of mostly resistant lines and a few moderate lines. The average DTI of cluster B-1 was $92.5 \pm 1.96 \%$, composed mostly of resistant lines and a few of moderate lines. The average DTI of cluster B-2 was $89.7 \pm 1.38 \%$, consisted of resistant lines and moderate lines. The average DTI of cluster B-3 was $80.1 \pm 1.15 \%$, consisted of of susceptible lines and moderate lines.

Table 6. Drought tolerance grouping of wheat cultivars based on drought tolerance index (DTI).

\begin{tabular}{|c|c|c|c|}
\hline $\begin{array}{c}\text { Drought Tolerance } \\
\text { Category }\end{array}$ & $\begin{array}{c}\text { Range of } \\
\text { DTI }\end{array}$ & $\begin{array}{c}\text { No. of } \\
\text { Cultivars }\end{array}$ & Entry No. (Name) \\
\hline Resistant & $>90 \%$ & 23 & $\begin{array}{l}1 \text { (Chunggyemil), } 4 \text { (Gobunmil), } 5 \text { (Keumgangmil), } 14 \text { (Younbaekmil), } 16 \\
\text { (Hanbaekmil), } 17 \text { (Sooan), } 18 \text { (Dajung), } 19 \text { (Goso), } 22 \text { (U14018), } 23 \\
\text { (U14021), } 26 \text { (U14045), } 27 \text { (U14046), } 31 \text { (FRIGUI 2), } 32 \text { (U14010), } 34 \\
\text { (U14050), } 35 \text { (U14053), } 36 \text { (U14055), } 37 \text { (U14078), } 39 \text { (AGIM } \\
\text { SINLIKA), } 40 \text { (MELANGE), } 41 \text { (BEDI), } 42 \text { (Allorca), } 45 \text { (Koudiat A2) }\end{array}$ \\
\hline Moderate & $80-90 \%$ & 33 & $\begin{array}{l}3 \text { (Alchanmil), } 8 \text { (Jinpummil), } 10 \text { (Anbaekmil), } 11 \text { (Sinmichalmil), } 12 \\
\text { (Jonongmil), } 13 \text { (Jokyoungmil), } 15 \text { (Sukangmil), } 20 \text { (ZAAFRANE), } 21 \\
\text { (U14014), } 24 \text { (U14038), } 25 \text { (U14040), } 30 \text { (U14076), } 33 \text { (U14031), } 38 \\
\text { (SINLIKAT), } 47 \text { (Mahon 73), 48 (Mahon 124), } 49 \text { (Roussla), } 50 \\
\text { (Cailloux), } 54 \text { (Mahon 73), } 55 \text { (Cailloux), } 56 \text { (Baroota 52), } 57 \text { (Soltane), } \\
60 \text { (Huguenot Bariole 360), } 61 \text { (Jenah Retifah 24), } 62 \text { (Mekki 13), } 63 \\
\text { (Sbei 7), } 64 \text { (Ble Dur 116), } 65 \text { (Ble Dur 870), 66 (Jenah Retifah 1), } 68 \\
\text { (Sbei 272), } 71 \text { (Maghrebi), } 75 \text { (Badri), } 76 \text { (Maghrebi 72) }\end{array}$ \\
\hline Susceptible & $<80 \%$ & 21 & $\begin{array}{l}2 \text { (Olgeurumil), } 6 \text { (Seodunmil), } 7 \text { (Saealmil), } 9 \text { (Joeunmil), } 28 \text { (U14054), } \\
29 \text { (U14057), } 43 \text { (Florence Aurore), } 44 \text { (Florence Aurore), } 46 \text { (Florence } \\
\text { 135), } 51 \text { (Mahon 73), } 52 \text { (Irakie 231), } 53 \text { (Mahon 124), } 58 \text { (Ariana 66), } \\
59 \text { (BT 2288), } 67 \text { (Jenah Retifah 24), } 69 \text { (Mahmoudi), } 70 \text { (Inrat 69), } 72 \\
\text { (Roussia), } 73 \text { (Maghrebi 72), } 74 \text { (Amal 72), } 77 \text { (Maghrebi 72) }\end{array}$ \\
\hline
\end{tabular}

Table 7. The most resistant cultivars to drought stress.

\begin{tabular}{cccc}
\hline \hline Entry No. & Name & Group & DTI (\%) \\
\hline 14 & Younbaekmil & Korean common wheat & 104.7 \\
34 & U14050 & Tunisian durum wheat & 102.6 \\
42 & Allorca & Tunisian common wheat & 113.6 \\
45 & Koudiat A2 & Tunisian common wheat & 106.8 \\
\hline
\end{tabular}




\section{DISCUSSION}

This study demonstrates that wheat cultivars are sensitive to drought treatment. Plant height, average leaf length, and leaf chlorophyll content decreased, whereas the number of tillers did not change. After re-watering, plant height and average leaf length continued to decrease, whereas leaf chlorophyll content showed similar values to that of the control and the number of tillers increased. Shoot dry weight also decreased, whereas days to flowering did not change. SSR analysis showed the genetic differences between the Korean and Tunisian cultivars based on drought tolerance.

Based on morphological trait measurement, the Korean common wheat and Tunisian common and durum wheat cultivars were affected by drought stress. Plant height and average leaf length did not recover fully, decreasing at the end of treatment and at 28 days after the end of treatment. Further, drought stress resulted in a reduced shoot dry weight. Thus, drought stress may result in the inhibition of

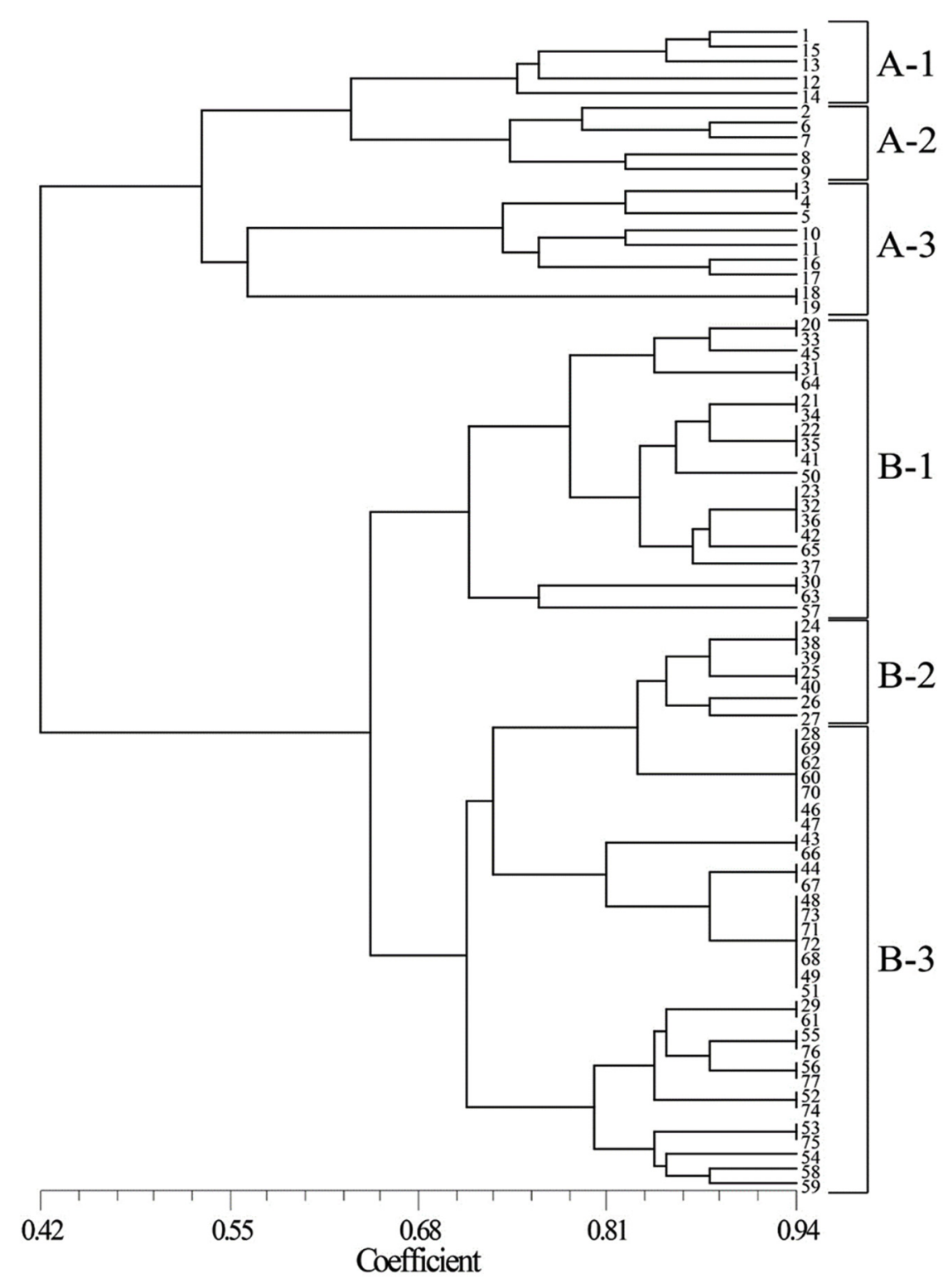

Fig. 3. SSR-based genetic relationship among 77 wheat cultivars. 
growth. According to Zhu (2001), water stress inhibits plant growth by inhibiting cell division. However, the leaf chlorophyll content of the drought-stressed plants decreased at the end of treatment, whereas it increased to levels similar to that of the control at 28 days after the end of the treatment. This indicates that the chlorophyll content of the newly produced leaves after re-watering in the treatment condition was similar to that in the control condition.

In terms of the number of tillers, Korean common wheat cultivars increased at both the end of treatment and 28 days after the end of treatment, whereas that of the Tunisian common wheat and durum wheat cultivars decreased at the end of treatment. According to Veesar et al. (2007), Indus66 , which is a more tolerant wheat genotype to water stress than other genotypes, formed a lower number of tillers. In addition, Castillo et al. (2007) reported that the number of non-productive tillers, which developed after restoration, increased with osmotic stress in rice. There might be a negative relationship between the number of non-productive tillers and drought tolerance.

Further, there was no clear difference between the control and treatment in terms of days to flowering, indicating that the number of tillers and days to flowering were not affected by drought stress. According to Foulkes et al. (2002), flowering date was typically neutral to drought stress.

Anjum et al. (2011) reported that plant height, stem diameter, and leaf area decreased under drought stress condition. These factors are related to average leaf length, and shoot dry weight. Further, there was a positive correlation between chlorophyll content (SPAD) and high transpiration efficiency, wherein SPAD could be utilized as an indicator of drought tolerance (Fotovat et al. 2007). Therefore, the calculation of DTI with morphological traits such as plant height, average leaf length, dry weight, and leaf chlorophyll weight can reflect drought tolerance.

Korean wheat and Tunisian wheat showed different DTIs at the end of treatment and 28 days after the end of treatment (Fig. 4). The DTI of Korean wheat cultivars was higher at the end of treatment than at 28 days after the end of treatment. However, the DTI of Tunisian common wheat and durum wheat cultivars were lower at the end of treatment than at 28 days after the end of treatment. This indicates that the tolerance to drought stress and the ability to restore must be considered separately. Costa et al. (1997) reported that the stress index between continuous stress and transient stress was different. Therefore, separate strategies should be used for these cultivars to improve drought tolerance.

The dendrogram showed distant relationship between the Korean and Tunisian cultivars (Fig. 3). Environmental conditions could affect genetic diversity (Li et al. 2012). Consequently, the genetic distance of Korean common wheat and Tunisian common wheat and durum wheat reflects the environmental differences between Korea and Tunisia.

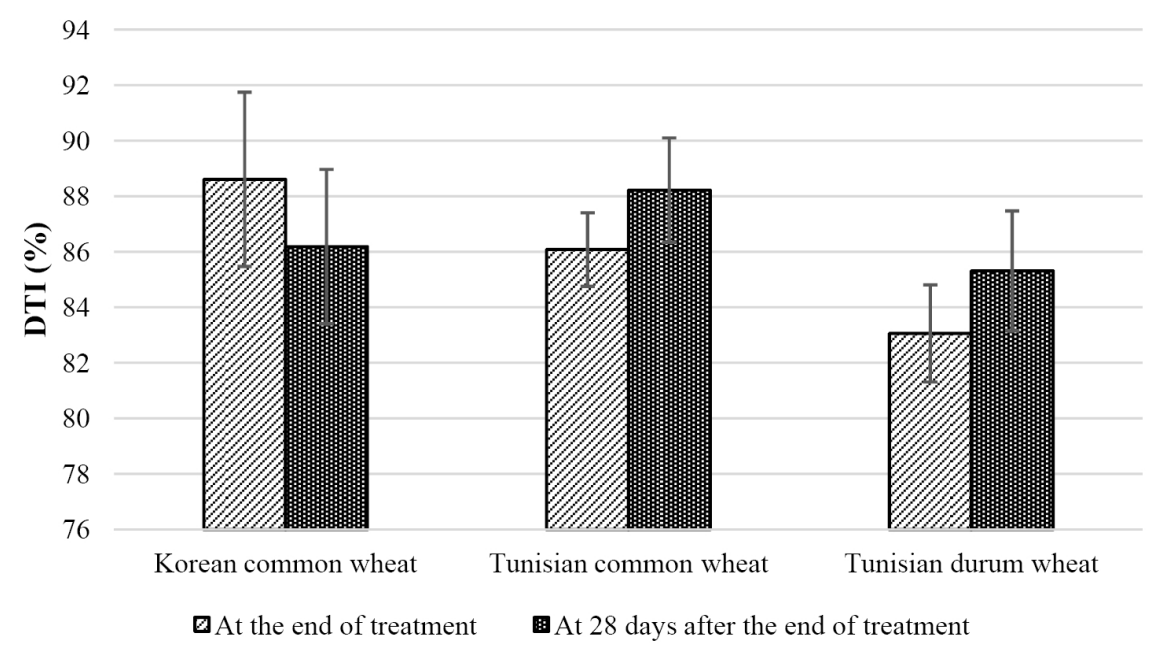

Fig. 4. Drought tolerance index (DTI) at the end of treatment and at 28 days after the end of treatment. 
In Tunisian cultivars, common wheat and durum wheat were completely mixed within the clusters, indicating that the SSR markers used in this study can be applied to both common wheat and durum wheat. In addition, both clusters $\mathrm{A}$ and $\mathrm{B}$ were categorized into some groups with drought tolerance. This suggests that the cluster analysis using SSR markers can be useful in evaluating drought tolerance in common wheat and durum wheat.

In conclusion, morphological traits and SSR markers could be used in evaluating drought tolerance in Korean and Tunisian wheat cultivars. It is necessary to establish an accurate standard to effectively evaluate tolerance to drought stress for wheat improvement. The results obtained in this study could help increase genetic resources and improve breeding programs for drought tolerance in wheat.

\section{ACKNOWLEDGMENT}

This work was supported by the National Research Foundation of Korea (NRF) grant funded by the Korea government (MEST) (No. 2012K1A3A1A09028123) and carried out with the support of "Cooperative Research Program for Agriculture Science \& Technology Development (Project title: Development of high yielding wheat with stress tolerance via molecular breeding strategies, Project No. PJ008031)", Rural Development Administration, Republic of Korea.

\section{REFERENCES}

Ali Z, Salam A, Azhar FM, Khan IA. 2007. Genotypic variation in salinity tolerance among spring and winter wheat (Triticum aestivum L.) accessions. South Afr. J. Bot. 73: 70-75.

Anjum SA, Xie XY, Wang LC, Saleem MF, Man C, Lei W. 2011. Morphological, physiological and biochemical responses of plants to drought stress. Afr. J. Agric. Res. 6: 2026-2032.

Brown ME, Funk CC. 2008. Food security under climate change. Science 319: 580-581.
Castillo EG, Tuong TP, Ismail AM, Inubushi K. 2007. Response to salinity in rice: Comparative effects of osmotic and ionic stresses. Plant Prod. Sci. 10: 159-170.

Ciucă M, Petcu E. 2009. SSR markers associated with membrane stability in wheat (Triticum aestivum L.). Romanian Agric. Res. 26: 21-24.

Costa LD, Vedove GD, Gianquinto G, Giovanardi R, Peressotti A. 1997. Yield, water use efficiency and nitrogen uptake in potato: influence of drought stress. Potato Res. 40: 19-34.

El Siddig MA, Baenziger S, Dweikat I, El Hussein AA. 2013. Preliminary screening for water stress tolerance and genetic diversity in wheat (Triticum aestivum L.) cultivars from Sudan. J. Genet. Eng. Biotechnol. 11: 87-94.

Farshadfar E, Jamshidi B, Cheghamirza K, da Silva JAT. 2012. Evaluation of drought tolerance in bread wheat (Triticum aestivum L.) using in vivo and in vitro techniques. Ann. Biol. Res. 3: 465-476.

Fotovat R, Valizadeh M, Toorchi M. 2007. Association between water-use efficiency components and total chlorophyll content (SPAD) in wheat (Triticum aestivum L.) under well-watered and drought stress conditions. J. Food Agric. Environ. 5: 225-227.

Foulkes MJ, Scott RK, Sylvester-Bradley R. 2002. The ability of wheat cultivars to withstand drought in UK conditions: formation of grain yield. J Agric. Sci. 138: 153-169.

Gupta PK, Varshney RK. 2000. The development and use of microsatellite markers for genetic analysis and plant breeding with emphasis on bread wheat. Euphytica 113: 163-185.

Jaleel CA, Manivannan P, Wahid A, Farooq M, Al-Juburi HJ, Somasundaram R, Panneerselvam R. 2009. Drought stress in plants: a review on morphological characteristics and pigments composition. Int. J. Agric. Biol 11: 100105.

Korea Seed \& Variety Service. 2014. http://www.seed.go.kr/. Li XJ, Xu X, Yang XM, Li XQ, Liu WH, Gao AN, Li LH. 2012. Genetic diversity of the wheat landrace Youzimai from different geographic regions investigated with morphological traits, seedling resistance to powdery mildew, gliadin and microsatellite markers. Cereal Res. Commun. 40: 95-106.

Lobell DB, Burke MB, Tebaldi C, Mastrandrea MD, Falcon WP, Naylor RL. 2008. Prioritizing climate change 
adaptation needs for food security in 2030 . Science 319 : 607-610.

Munns R, James RA, Läuchli A. 2006. Approaches to increasing the salt tolerance of wheat and other cereals. J. Exp. Bot. 57: 1025-1043.

Pan XY, Wang YF, Wang GX, Cao QD, Wang J. 2002. Relationship between growth redundancy and size inequality in spring wheat population mulched with clear plastic film. Acta Phytoecol. Sinica 26: 177-184.

Quarrie SA, Dodig D, Pekiç S, Kirby J, Kobiljski B. 2003. Prospects for marker-assisted selection of improved drought responses in wheat. Bulg. J. Plant Physiol. 2003: 83-95.

Rai MK, Kalia RK, Singh R, Gangola MP, Dhawan AK. 2011. Developing stress tolerant plants through in vitro selection-An overview of the recent progress. Environ. Exp. Bot. 71: 89-98.

Rajaram S. 2001. Prospects and promise of wheat breeding in $21^{\text {st }}$ century. Euphytica 119: 3-15.

RDA. 2014. RDA-Genebank Information Center. http://www. genebank.go.kr/.
Shahzad A, Ahmad M, Iqbal M, Ahmad I, Ali GM. 2012. Evaluation of wheat landrace genotypes for salinity tolerance at vegetative stage by using morphological and molecular markers. Genet. Mol. Res. 11: 679-692.

Takeda S, Matsuoka M. 2008. Genetic approaches to crop improvement: responding to environmental and population changes. Nat. Rev. Genet. 9: 444-457.

USDA. 2014. The Agricultural Research Service - Germplasm Resources Information Network (ARS-GRIN). http://www. ars-grin.gov/.

USDA. 2014. The Agricultural Research Service - The GrainGenes 2.0. http://wheat.pw.usda.gov/.

Veesar NF, Channa AN, Rind MJ, Larik AS. 2007. Influence of water stress imposed at different stages on growth and yield attributes in bread wheat genotypes Triticum aestivum L. Wheat Inform. Ser. 104: 15-19.

Yıldırıma M, Kılıçb H, Kendalb E, Karahan T. 2011. Applicability of chlorophyll meter readings as yield predictor in durum wheat. J.Plant Nutri. 34: 151-164.

Zhu JK. 2001. Plant salt tolerance. Trends Plant Sci. 6: 66-71. 